\title{
Infrared microspectroscopic imaging as a probing tool to fast distinguish chemical compositions in calcified deposits of prostatic calculi and calcific tendonitis
}

\author{
Shan-Yang Lin ${ }^{\mathrm{a}, *}$, Tieh-Kang $\mathrm{Wu}^{\mathrm{a}}$, Hong-Jen Chiou ${ }^{\mathrm{b}}$, Ted Hueih-Shing $\mathrm{Hsu}^{\mathrm{c}}$ and \\ Chih-Cheng Lin ${ }^{\text {a }}$ \\ ${ }^{a}$ Department of Biotechnology, Yuanpei University, Hsin-Chu, Taiwan, China \\ ${ }^{\mathrm{b}}$ Department of Radiology, Taipei Veterans General Hospital, and School of Medicine, \\ National Yang-Ming University, Taipei, Taiwan, China \\ ${ }^{\mathrm{c}}$ Division of Urology, Department of Surgery, Lotung Pohai Hospital, Lotung, Ilan, Taiwan, China
}

\begin{abstract}
The specificity and homogeneity of the real compositional components within the calcified deposits of prostatic calculi and calcific tendonitis were investigated using Fourier transform infrared (FT-IR) microspectroscopy with or without automatic imaging system. The second-derivative analysis was also applied to differentiate the overlapping components of individual spectra for the calcified samples. The FT-IR microscopic imaging results of present study indicate that the complicated components such as protein, type B or type A carbonated apatite, brushite and calcium oxalate monohydrate were contained in the calcified tissue of prostatic tissue, but the protein, type A and type B carbonated apatites were mainly included in the calcific tendonitis. However, the traditional manually single-point FT-IR spectral result only reveals a little component contained in the calcified tissues, leading to an inaccurate diagnose of the complicated components in the calcified mixture.
\end{abstract}

Keywords: FT-IR mapping, second-derivative analysis, calcified tissue, component

\section{Introduction}

Biological mineralization is a sophisticated process by which inorganic minerals are deposited in the cellular or extracellular matrix of living organisms $[2,13,25]$. Numerous mineralized human tissues such as bone and teeth are naturally produced to contribute to the human body, but some crystal deposition diseases belonging to one of biomineralization processes in different human organs may cause much disorders and pathological symptoms [35,36]. Pathologies of biomineralization can occur in a number of ways and throughout the life span. The calcification occurred at unwanted tissue sites leads to dysfunction, disease and death. Although different calcification-related diseases such as atherosclerosis, stone-forming diseases, cataracts, urological stones, skin disorders, neurological disorders, strokes and heart attacks have been found [12,20], many approaches to the diagnosis and treatment of these calcifications will become more available in the future.

\footnotetext{
* Corresponding author: Prof. Shan-Yang Lin, Ph.D., Department of Biotechnology, Yuanpei University, Hsin Chu, Taiwan, China. Tel.: +886 03 5381183 8157; Fax: +886 03 6102328; E-mail: sylin@ mail.ypu.edu.tw.
} 
Tissue calcification has been commonly diagnosed using a complicated process of histological or immunopathological examination in hospital, in which the anatomical and morphological structures of the calcified lesions can only be identified by the experienced researchers. Recently, the application of Fourier transform infrared (FT-IR) microspectroscopy to clinical studies has been focused on the diagnosis of diseases and laboratory analyses of pathological samples, particularly for characterization of the biological mineralization $[1,4,16]$. In the traditional FT-IR analysis without microscopy, this technique allows identifying any organic or inorganic molecules in the calcified samples by grinding the sample with $\mathrm{KBr}$ powder or sealing the sample within two $\mathrm{KBr}$ pellets for spectral determination after compression $[6,8,11]$. In our previous studies, several human calcified tissues, such as calcinosis cutis, skin pilomatrixoma, cornea, senile cataractous lens, vitreous asteroid bodies, sclera and superior vesical artery had been investigated using this powerful and convenient vibrational microspectroscopic technique $[7-11,23,27,28]$. However, the main drawback of this technique is that the manual singlepoint random determination at microscopic level cannot really reflect the spatial distribution of all the components in the mixture, leading to possibly inaccurate diagnose of the complicated components in the calcified mixture. The heterogeneous distribution of the components within $\mathrm{KBr}$ disc may cause an incorrect conclusion by only few sampling points through this traditional IR spectral analysis.

More recently, a powerful FT-IR microspectroscopic mapping system has also been established for applying to biosciences $[18,41]$. This system combining the light microscopy, FT-IR spectroscopy and a mapping stage provides spatially resolved information on the basis of chemical composition of the different structural components. The spectroscopic images are automatically obtained by mapping with a standard microscope equipped with an $X Y$ stage and a computer-controlled motorized stage. The IR spectra of different components located within the sample can be possibly determined via point-by-point mapping analysis $[22,26]$. This system can not only image the heterogeneous regions of tissue but also provide spectroscopic and spatial information. As the image contrast is based on the vibrational signature of the tissue components, FT-IR imaging does not require the use of dyes, tags or stains. Thus, compared with conventional histological techniques, IR imaging of tissues may simplify sample preparation procedures and minimizes sample modifications. Thus, this FT-IR microspectroscopic mapping system can rapidly screen and detect the real composited components contained in the tissue via automatic scanning technique.

The aim of this study was attempted to evaluate and compare the specificity and homogeneity of the real compositional components within the calcified deposits of prostatic calculi and calcific tendonitis by using FT-IR microspectroscopic imaging system.

\section{Materials and methods}

\subsection{Patients}

Prostatic calculi were obtained from nine patients (mean age: 76) diagnosed having benign prostatic hyperplasia with lower urinary tract symptoms. The level of serum prostatic-specific antigen was within $0-12.63 \mathrm{ng} / \mathrm{ml}$. Another calcified sample was got from a 49 year-old female patient suffered from shoulder pain of calcific tendonitis diagnosed by a high-resolution ultrasonography and a Siemens S2000 system with the 9L4 linear transducer. These studies were approved by Institutional Review Board at the Lotung Pohai Hospital and Taipei Veterans General Hospital, according to the declaration of Helsinki. 


\subsection{Materials}

Hydroxyapatite (HA), calcium oxalate monohydrate (COM) and calcium oxalate dihydrate (COD) as standard references were purchased from Nacalai Tesque, Inc. (Tokyo, Japan), and used without further purification.

\subsection{Specimen collection and sample preparation for FT-IR analysis}

All the calcified samples were isolated, washed with double distilled water for two times, dried at $25^{\circ} \mathrm{C}, 50 \% \mathrm{RH}$ and then sent for the histopathological examination and spectral analysis. A trace amount of each fine calcified sample was sealed within two $\mathrm{KBr}$ pellets by a hydraulic press under $400 \mathrm{~kg} / \mathrm{cm}^{2}$ compression pressure for $15 \mathrm{~s}$ to form a $\mathrm{KBr}$ disc $[7,8,11,23,27,28]$. The fine powders distributed within $\mathrm{KBr}$ disc were observed and photographed by infrared microscope (IRT-5000-16/FTIR-6200, Jasco Co., Tokyo, Japan) with a video camera.

\subsection{FT-IR microspectroscopic study with or without mapping technique}

Each $\mathrm{KBr}$ disc prepared from different samples was examined to determine the chemical component using an FT-IR microspectroscopy (IRT-5000-16/FTIR-6200, Jasco Co.) equipped with an MCT detector via a transmission technique $[7,8,11,23,27,28]$. The traditional single-point FT-IR spectral analysis was randomly detected via a manual determination. The IR spectra over the range of $2000-650 \mathrm{~cm}^{-1}$ were carried out at 200 scans under a resolution of $4 \mathrm{~cm}^{-1}$. In addition, an appropriate sample area was selected, and the IR spectra were collected successively from the actual analysis area by an automatic $X Y Z$ mapping stage (IPS-5000, Jasco Co.). This mapping stage was employed to obtain full IR spectra of calcified sample at any random area of $\mathrm{KBr}$ disc through whole area by automatically point-by-point mapping technique [22,26]. The sampling aperture was set at $100 \mu \mathrm{m} \times 100 \mu \mathrm{m}$, each spectrum was performed at 100 scans with the resolution of $4 \mathrm{~cm}^{-1}$. The map of size was $10 \times 10$ points in $1 \mathrm{~mm}^{2}$, leading to the acquisition of 100 spectra.

\subsection{Spectroscopic data acquisition and processing}

All spectral data processing and image assembly were performed using a spectra manager and GRAMS spectroscopy software suite. Second-derivative FT-IR spectral analysis was applied to locate the position of the overlapping components of individual spectra for the calcified samples.

\section{Results}

\subsection{IR spectra of standard references}

The FT-IR spectra of pure standard references of HA, COM and COD by a manual single-point determination are shown in Fig. 1(A). The IR spectrum of HA indicates typical IR absorption peaks at 961, 1031 and $1092 \mathrm{~cm}^{-1}$ corresponding to the $\nu_{1}$ and $\nu_{3}$ stretching modes of phosphate $[1,3,4,6-8$, $11,16,23,27,28]$. A strong peak at $1619 \mathrm{~cm}^{-1}\left(\nu_{\text {as }}(\mathrm{COO})\right)$, two moderate intensity sharp peaks at 1320 $\left(\nu_{\mathrm{s}}(\mathrm{COO})\right)$ and $780 \mathrm{~cm}^{-1}(\delta(\mathrm{O}-\mathrm{C}=\mathrm{O})+\nu(\mathrm{M}-\mathrm{O}))$, and two weak peaks at 948 and $885 \mathrm{~cm}^{-1}$ (a combination modes of $\nu_{\mathrm{s}}(\mathrm{CO})$ and $\left.\delta(\mathrm{O}-\mathrm{C}=\mathrm{O})\right)$ were observed in the IR spectrum of $\mathrm{COM}$, but two strong IR peaks at 1627 and $1327 \mathrm{~cm}^{-1}$ with one weak peak at $781 \mathrm{~cm}^{-1}$ were characterized in the IR spectrum of COD $[5,17,29]$. 


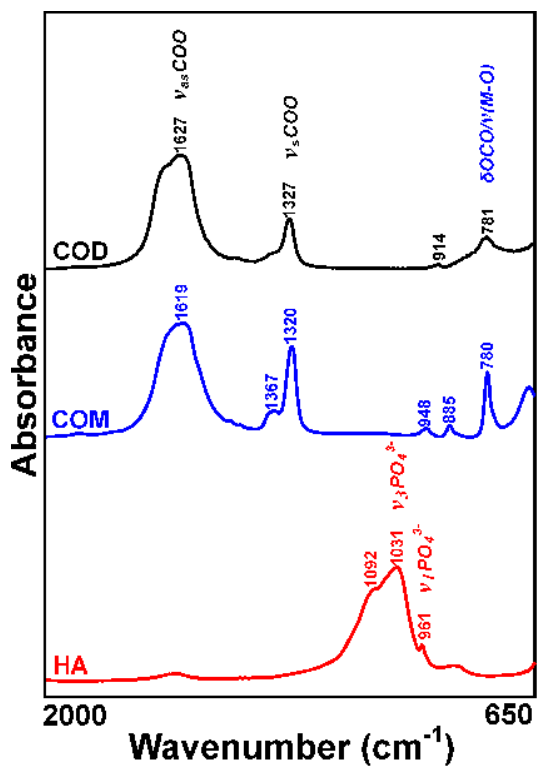

(A)

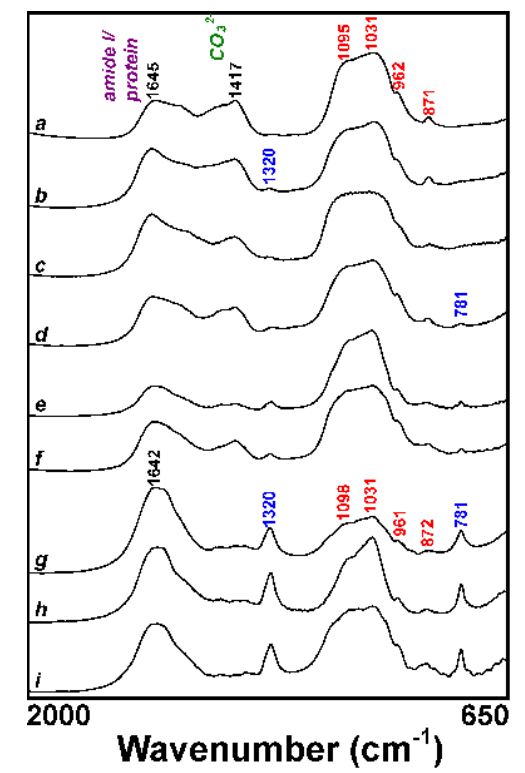

(B)

Fig. 1. FT-IR spectra of pure standard references of HA, COM and COD (A) and the prostatic calculi isolated from 9 patients $(a-i)$ using a manual single-point random analysis (B). (Colors are visible in the online version of the article; http://dx.doi.org/10.3233/SPE-2011-0510.)

\subsection{Compositional components of calcified deposits in prostatic calculi}

Figure 1(B) shows FT-IR spectra of the prostatic calculi isolated from 9 patients (samples $a-i$ ) using a manual single-point random analysis. It clearly indicates that all the IR spectral patterns could be discriminated into two types in the absence or presence of IR peak at $781 \mathrm{~cm}^{-1}$, type I $(a-c)$ and type II $(d-i)$. Moreover, type II might be further subdivided into two sub-groups, one with weak peak intensity at $781 \mathrm{~cm}^{-1}(d-f)$ and another with strong one $(g-i)$. The specific IR spectral peaks at 1645 and $1642 \mathrm{~cm}^{-1}$ were assigned to the amide I band of protein [21,24]. The $\mathrm{C}-\mathrm{O}$ bending vibration $\left(\nu_{2}\right)$ at about 872 (871) $\mathrm{cm}^{-1}$ and the $\mathrm{C}-\mathrm{O}$ stretching $\left(\nu_{3}\right)$ at around $1417 \mathrm{~cm}^{-1}$ were the characteristic bands of carbonate in HA, respectively [19,39]. The peak at $1320 \mathrm{~cm}^{-1}$ might be also due to the symmetric $\mathrm{C}=\mathrm{O}$ stretch of oxalate [17]. From FT-IR spectra detected by single-point determination, it seems to be concluded that all the samples mainly consisted of HA (1417, 1095 (1098), 1031, $962(961)$ and $\left.871(872) \mathrm{cm}^{-1}\right)$ and protein $\left(1645(1642) \mathrm{cm}^{-1}\right)$, but COM (1320 and $\left.781 \mathrm{~cm}^{-1}\right)$ was further contained in samples $d-i$.

The optical photo-image of fine ground calculi powders (sample $b$, as an example) sealed within two $\mathrm{KBr}$ pellets is displayed in Fig. $2 \mathrm{~A}$, in which the area of red line was the mapping area. The representative IR line spectra collected from mapping stage of sample $b$ are indicated in Fig. 2(B). It clearly indicates that some IR spectra were found to have a spectral peak at $781 \mathrm{~cm}^{-1}$, which was assigned to calcium oxalate $[5,17,29]$. Several IR spectra had also exhibited a peak at $1320 \mathrm{~cm}^{-1}$ due to COM. However, many IR spectra did not show above two peak positions. From these IR spectra determined by pointby-point mapping analysis, sample $b$ was constructed by protein $\left(1645 \mathrm{~cm}^{-1}\right)$, HA $(1095,1031,1417$ and $871 \mathrm{~cm}^{-1}$ ) and COM (781 and $\left.1320 \mathrm{~cm}^{-1}\right)$, which was significantly different from that of FT-IR spectrum of sample $b$ by a manual single-point determination (Fig. 1(B)-b). FT-IR image of the peak area 

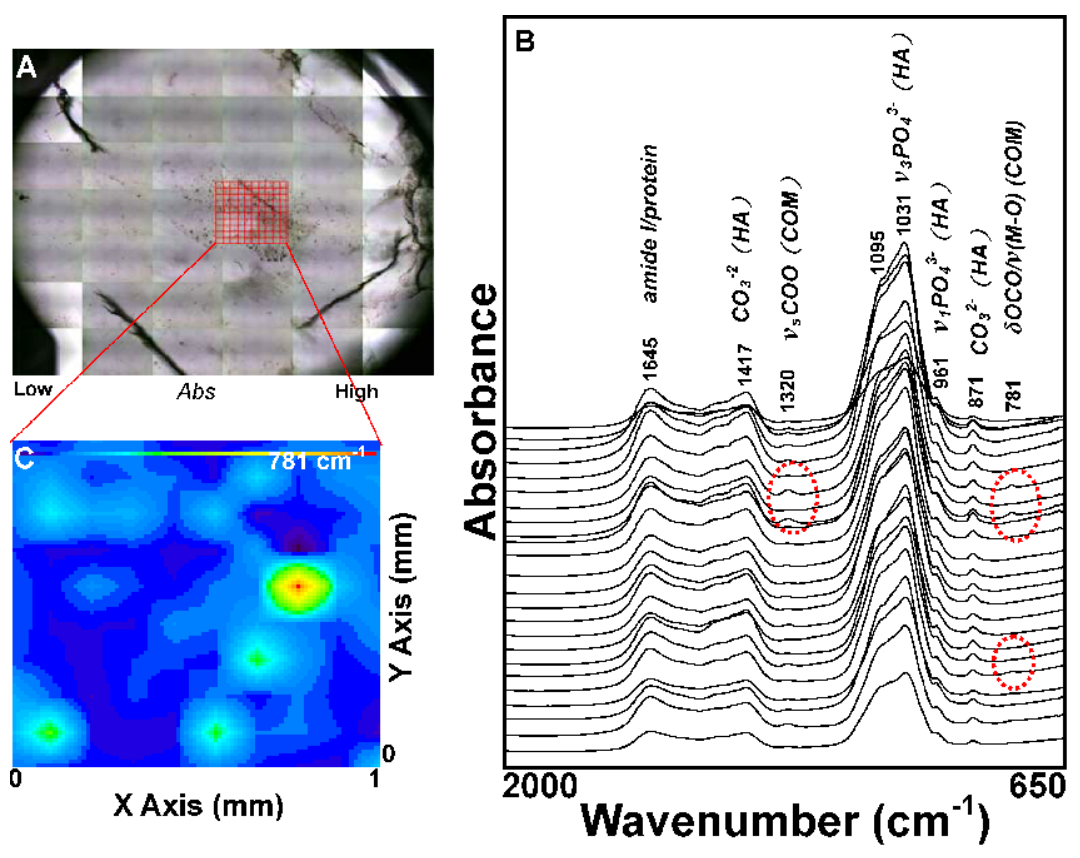

Fig. 2. Optical image of fine powders sealed within two KBr pellets for sample $b$ (A), the representative IR line spectra collected from mapping stage (B) and spectroscopic image plane representing the area under the IR peaks at $781 \mathrm{~cm}^{-1}$ of a sample (C). Key: The area shown is $1.0 \mathrm{~mm} \times 1.0 \mathrm{~mm}$. Red areas represent the highest absorbance, while blue areas denote low IR absorbance. (The colors are visible in the online version of the article; http://dx.doi.org/10.3233/SPE-2011-0510.)

intensity distribution of $781 \mathrm{~cm}^{-1}$ assigned to the presence of COM in the calcified sample is indicated in Fig. 2C. The red areas represent the highest absorbance with higher content, whereas the deep blue areas denote low IR absorbance. Because the peak at $781 \mathrm{~cm}^{-1}$ represented the existence of COM, the un-uniform color display revealed the heterogeneous distribution of COM in the calculus, leading to the missing detection of COM in sample $b$ after a manual single-point analysis.

\subsection{Compositional components of calcified deposits in calcific tendonitis}

Four FT-IR images of the intensity distributions of the representative vibrational modes (protein, phosphate and carbonate) and the IR spectra for five defined positions in the calcified sample isolated from tendon of calcific tendonitis are presented in Fig. 3. The red line in Fig. 3 displays pixel locations from which the single-pixel IR spectra were taken and indicates the line scanning direction from left to right. These non-smoothed, single-pixel spectra are all plotted on the same scale. Figure 4 shows the corresponding infrared line scanning spectra. It is evident that all the FT-IR spectra shown in Figs 3 and 4 were similar, indicating similar compositions were produced at different positions in tendon samples. Several IR peaks near 1651 or 1654 (amide I of protein), 1450 or $1449\left(\mathrm{CH}_{2} / \mathrm{CH}_{3}\right.$ bending of lipid or amide III of protein), 1417 (carbonate), 1034 ( $\nu_{3}$ phosphate stretching), 959 ( $\nu_{1}$ phosphate stretching) and $873\left(\nu_{2}\right.$ carbonate mode) $\mathrm{cm}^{-1}$ were observed [3,5,17,21,22,24,29]. The appearance of IR peaks at 1034 , and $959 \mathrm{~cm}^{-1}$ was similar to that of the IR spectrum of HA, indicating the calcified deposit predominantly consisted of HA [3,17,29]. 

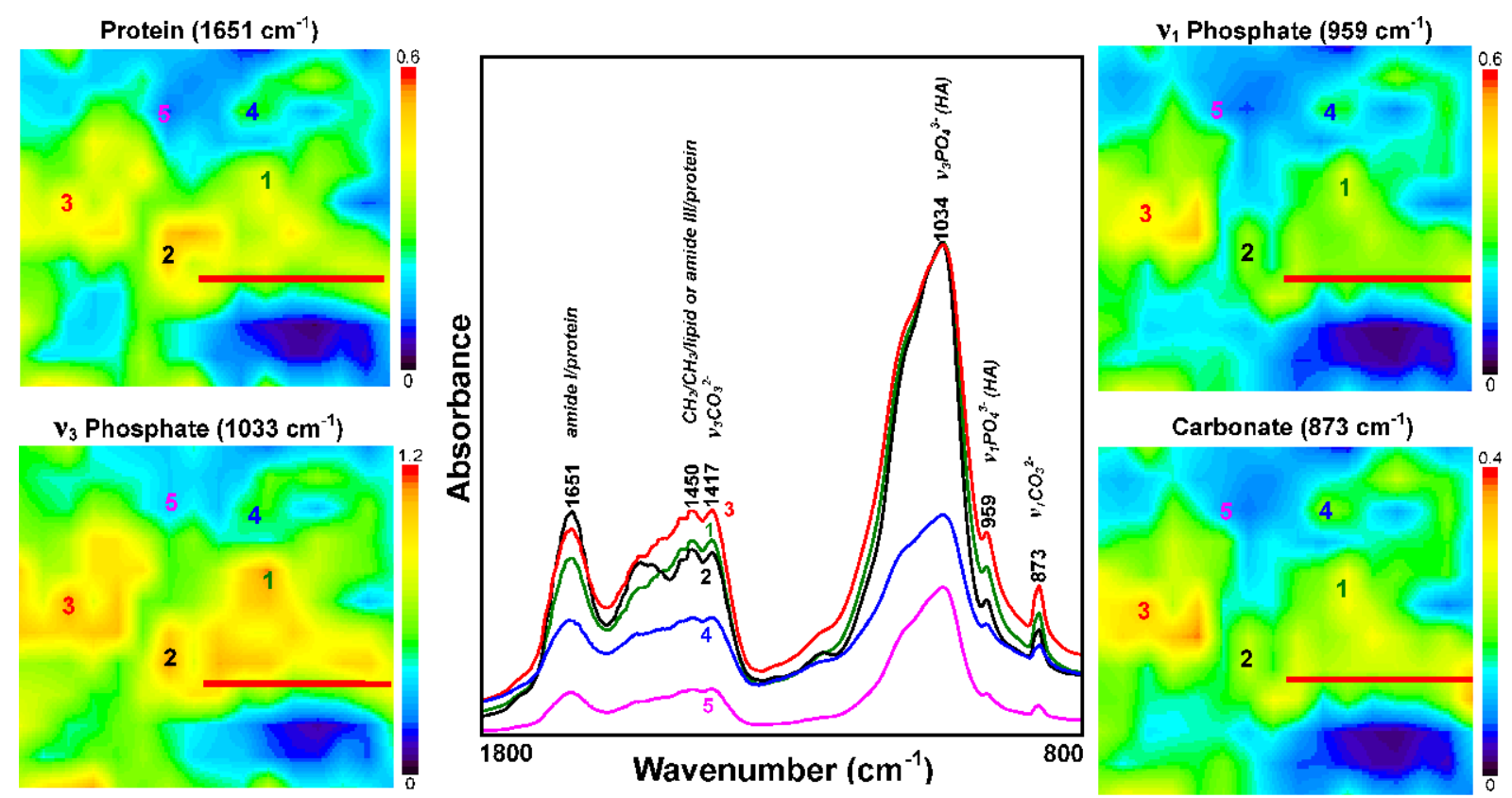

Fig. 3. Four FT-IR images of the intensity distributions of the representative vibrational modes (protein, phosphate and carbonate) and the IR spectra for five defined positions in the calcified sample isolated from tendon of calcific tendonitis. (The colors are visible in the online version of the article; http://dx.doi.org/10.3233/SPE-2011-0510.)

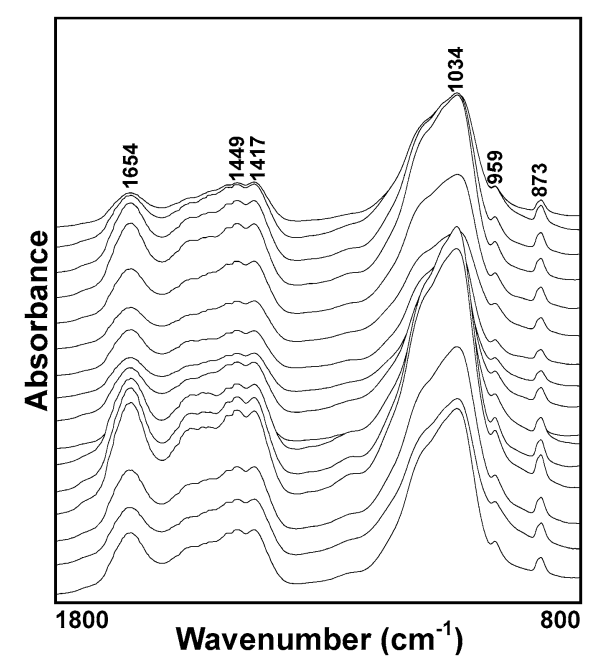

Fig. 4. The non-smoothed, single-pixel IR line scanning spectra of red line displayed in Fig. 3. Moving from left to right along red line corresponds to the IR spectra shown from bottom to top.

\section{Discussion}

Recently, the use of vibrational microspectroscopy has shown great potential over other diagnostic techniques to successfully investigate the chemical composition of the diseased tissue, rather than histological pathology alone $[18,31,40,41]$. In the present study the manual single-point random FT-IR 
spectral determination reveals that different chemical compositions were contained in the prostatic calculi for 9 patients as shown in Fig. 1(B). The samples $a-c$ only consisted of HA and protein but the samples $d-i$ were constructed by HA, protein and COM. Obviously, the manual single-point random analytical method was not sufficient to provide the available information of the composition of the calculi at any time, leading to a possibly inaccurate conclusion.

Infrared microspectroscopic imaging is rapidly becoming a key technique for biomedical spectroscopy since it provides spatially resolved chemical characterization of microscopic areas $[18,31,40,41]$. The strengths and adaptability of this technique derive not only from the ability to determine chemical compositions and component distribution within a sample, but also from the ability to extract localized molecular information related to the sample architecture. In the present study, this imaging technique may provide information on the type of mineral phase and the changes in mineral and matrix compositions in the calcified samples. Here, the real chemical compositions of prostatic calculi or calcific tendonitis were easily obtained from the distribution of chemical components in the calcified tissue by one-step FT-IR microspectroscopic mapping system. The characteristic absorption bands were obtained to localize and identify component itself. We found that the mapping data exhibited three components in prostatic calculi or two components in calcific tendonitis rather than only a little component determined by traditional FT-IR microspectroscopy.

The analysis of compositional components in sample using FT-IR microspectroscopy may be also enhanced by computing the second-derivative IR spectrum [32,38]. The second-derivative IR spectroscopy cannot only identify the major components from a variety of sources but also find the tiny differences among the similar samples. In the study of mineralization, an FT-IR spectroscopic analysis has been extensively applied to determine the locations of $\nu_{1}, \nu_{3}$ phosphates $\left(900-1200 \mathrm{~cm}^{-1}\right)$ and $\nu_{2}$ carbonate $\left(860-890 \mathrm{~cm}^{-1}\right)$ of mineralized materials, particularly for the evaluation of the maturity of HA $[4,14]$. It has been reported that the poorly crystalline, immature HA having specific peaks at 960, 985, 1020, 1038, 1055 and $1075 \mathrm{~cm}^{-1}$ might shift to the matured crystalline HA with characteristic peaks at 960 , 983, 999, 1030, 1055, 1075, 1096 and $1116 \mathrm{~cm}^{-1}$ in the living organs with time [4,14]. The former belonged to the non-stoichiometric apatites while the latter were stoichiometric apatites.

In the present study, several unique peaks at 961, 983, 1017, 1028, 1072, 1092 and $1119 \mathrm{~cm}^{-1}$ appeared in the second-derivative IR spectrum of the pure standard reference of HA, indicating that HA used was a mature and stoichiometric apatite without containing carbonate (Fig. 5a). However, the IR spectra of three representative samples isolated from three patients exhibited different IR spectra from that of HA. Figure $5 \mathrm{~b}$ shows several unique peaks at 1153, 1012, 989, 956 and $873 \mathrm{~cm}^{-1}$ in the IR spectrum of sample $b$. The IR peaks at 1153,1012 and $989 \mathrm{~cm}^{-1}$ were assigned to the brushite $\left(\mathrm{CaHPO}_{4} \cdot 2 \mathrm{H}_{2} \mathrm{O}\right)$, which was believed to be a precursor of apatite $[15,42]$. The peaks at 956 and $873 \mathrm{~cm}^{-1}$ corresponded to the $\nu_{1} \mathrm{PO}_{4}{ }^{3-}$ of $\mathrm{HA}$ and carbonate ions located in $\mathrm{PO}_{4}{ }^{3-}$ sites of HA [14, $15,19,42]$. The IR spectrum of sample $d$ indicates in Fig. 5c, in which the peaks at 1149 and $992 \mathrm{~cm}^{-1}$ were due to the brushite but the peaks at 1026 and $953 \mathrm{~cm}^{-1}$ were assigned to phosphate of HA, and the peaks at 874 and $783 \mathrm{~cm}^{-1}$ were related to the carbonate ions located in $\mathrm{PO}_{4}{ }^{3-}$ sites of $\mathrm{HA}$ and COM, respectively. The sample $h$ shows the similar IR spectrum to that of sample $d$, but predominate IR peaks at 1115-1102, 1027 and $958 \mathrm{~cm}^{-1}$ strongly illustrating the matured HA in the calcified sample $h$ (Fig. 5d). In addition, a strong IR peak at $782 \mathrm{~cm}^{-1}$ was also found, showing a higher content of COM in the calcified sample. This strongly implies that the biomineralization process in some calcified prostatic tissues was still proceeding.

On the other hand, two small second-derivative IR spectral peaks at 1020 and $1030(1031) \mathrm{cm}^{-1}$ were observed for the calcified deposits of tendon in calcific tendonitis (Fig. 6). It has been reported that 

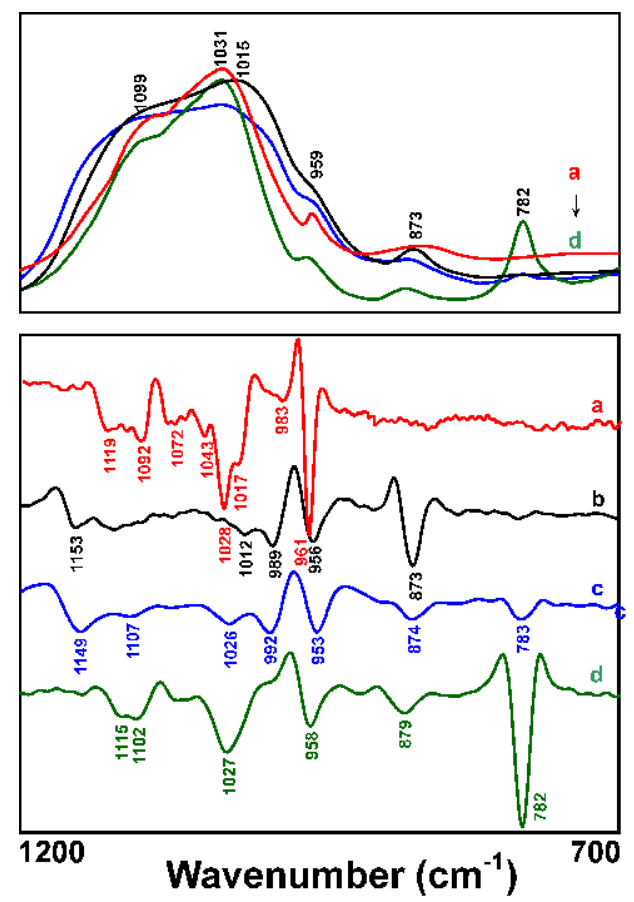

Fig. 5. Second-derivative IR spectra of the $800-1200 \mathrm{~cm}^{-1}$ region for HA and the representative calcified samples isolated from prostatic calculi. Key: a, HA; prostatic calculi: b, sample b; c, sample $d$; d, sample $h$. (Colors are visible in the online version of the article; http://dx.doi.org/10.3233/SPE-2011-0510.)

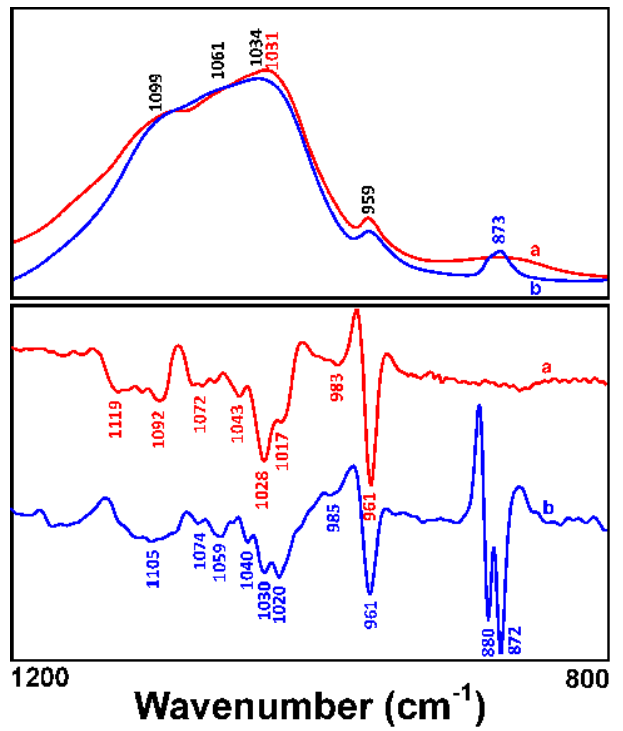

Fig. 6. Second-derivative IR spectra of the $900-1200 \mathrm{~cm}^{-1}$ region for HA (a) and the calcified sample of tendon calcification (b). (Colors are visible in the online version of the article; http://dx.doi.org/10.3233/SPE-2011-0510.) 
a peak near $1020 \mathrm{~cm}^{-1}$ is attributed to the $\nu_{3}$ vibration of $\mathrm{PO}_{4}{ }^{3-}$ in non-stoichiometric apatites but a peak at $1030 \mathrm{~cm}^{-1}$ is indicative of the $\nu_{3}$ vibration of $\mathrm{PO}_{4}{ }^{3-}$ in stoichiometric apatites [14,15]. Both peaks appeared in the second-derivative IR spectra of the calcified sample of tendon, suggesting the mineralization is still in progress.

In fully mature apatite, the carbonate ions can occupy two anionic sites of the apatite structure: $\mathrm{CO}_{3}{ }^{2-}$ ions may substitute either $\mathrm{OH}^{-}$anions (type A carbonate) or the $\mathrm{PO}_{4}{ }^{3-}$ (type $\mathrm{B}$ carbonate) in the crystal lattice of apatites or may be in unstable locations $[34,37]$. The carbonate bands showed three components in the IR spectral region of $860-890 \mathrm{~cm}^{-1}$ as follows: a band near $871 \mathrm{~cm}^{-1}$ was assigned to type B carbonated apatite, a band at $878 \mathrm{~cm}^{-1}$ responded to type A carbonated apatite, and a band at $866 \mathrm{~cm}^{-1}$ was attributed to an unstable carbonate location [30,33]. From the second-derivative IR spectra of calcified samples in Figs 5 and 6, it clearly reveals that type B carbonated HA $\left(873\right.$ and $\left.874 \mathrm{~cm}^{-1}\right)$ was contained in calcified sample of samples $b$ and $d$ of prostatic calculi, but sample $h$ of prostatic calculi was constructed by type A carbonated HA $\left(879 \mathrm{~cm}^{-1}\right)$. Whereas the second-derivative IR spectra of the calcified sample of tendonitis exhibited two sharp peaks at 880 and $872 \mathrm{~cm}^{-1}$, indicating the type A and type $\mathrm{B}$ carbonated apatites were together contained in the calcified deposits of tendon, as compared to the HA reference without containing carbonates.

\section{Conclusions}

The result of present study indicates that the complicated components such as protein, type B or type A carbonated apatite, brushite and COM were contained in the calcified tissue of prostatic tissue, but the protein, type A and type B carbonated apatites were major included in the calcific tendonitis. Moreover, the FT-IR spectroscopic mapping system and second-derivative IR spectroscopy are a workable technique to quickly screen and identify the real compositional components existed in the calcified samples isolated from both prostatic calculi and calcific tendonitis.

\section{Acknowledgements}

The authors thank Misses Wen-Ting Cheng and Yu-Ting Huang for their technical assistance. This work was supported by National Science Council, Taipei, Taiwan, Republic of China (NSC-97-2320B075-054-MY3).

\section{References}

[1] S. Bohic, D. Heymann, J.A. Pouëzat, O. Gauthier and G. Daculsi, C. R. Acad. Sci. III 321 (1998), 865.

[2] A.L. Boskey, J. Cell Biochem. 72(Suppl. 30,31) (1998), 83.

[3] A.L. Boskey and R. Mendelsohn, Vib. Spectrosc. 38 (2005), 107.

[4] A. Carden and M.D. Morris, J. Biomed. Opt. 5 (2000), 259.

[5] F. Cariati, L. Rampazzi, L. Toniolo and A. Pozzi, Studies in Conservation 45 (2000), 180.

[6] P. Carmona, J. Bellanato and E. Escolar, Biospectroscopy 3 (1997), 331.

[7] K.H. Chen, W.T. Cheng, M.J. Li and S.Y. Lin, Graefe's Arch. Clin. Exp. Ophthal. 244 (2006), 407.

[8] K.H. Chen, W.T. Cheng, M.J. Li, D.M. Yang and S.Y. Lin, J. Microsc. 219 (2005), 36.

[9] K.H. Chen, M.J. Li, W.T. Cheng, T. Balic-Zunic and S.Y. Lin, Int. J. Exp. Pathol. 90 (2009), 74.

[10] W.T. Cheng, M.T. Liu, H.N. Liu and S.Y. Lin, Microsc. Res. Tech. 68 (2005), 75.

[11] H.J. Chiou, S.C. Hung, S.Y. Lin, Y.S. Wei and M.J. Li, Rheumatology 49 (2010), 548.

[12] N. Ciftçioğlu and D.S. McKay, Pediatr. Res. 67 (2010), 490. 
[13] H. Cölfen, Nat. Mater. 9 (2010), 960.

[14] S.J. Gadaleta, N.P. Camacho, R. Mendelsohn and A.L. Boskey, Calif. Tissue Int. 58 (1996), 17.

[15] S.J. Gadaleta, E.P. Paschalis, F. Betts, R. Mendelsohn and A.L. Boskey, Calif. Tissue Int. 58 (1996), 9.

[16] R. Garimella, X. Bi, H.C. Anderson and N.P. Camacho, Bone 38 (2006), 811.

[17] J.R. Guerra-López, J.A. Güida and C.O. Della Védova, Urol. Res. 38 (2010), 383.

[18] J. Guilment, S. Markel and W. Windig, Appl. Spectrosc. 48 (1994), 320.

[19] X. Guo, W. Wang, G. Wu, J. Zhang, C. Mao, Y. Deng and H. Xia, New J. Chem. 35 (2011), 663.

[20] P.B. Halverson, Curr. Opin. Rheumatol. 8 (1996), 259.

[21] P.I. Haris and D. Chapman, Meth. Mol. Biol. 22 (1994), 183.

[22] T.H.S. Hsu, S.Y. Lin, C.C. Lin and W.T. Cheng, Urol. Res. 39 (2011), 165.

[23] T.H.S. Hsu, S.Y. Lin, C.C. Lin, W.T. Cheng and M.J. Li, Urol. Res. 37 (2009), 253.

[24] M. Jackson and H.H. Mantsch, Crit. Rev. Biochem. Mol. Biol. 30 (1995), 95.

[25] K. Kawasaki, A.V. Buchanan and K.M. Weiss, Annu. Rev. Genet. 43 (2009), 119.

[26] T.H. Lee and S.Y. Lin, Eur. J. Pharm. Sci. 23 (2004), 117.

[27] S.Y. Lin, K.H. Chen, W.T. Cheng, C.T. Ho and S.L. Wang, Microsc. Microanal. 12 (2007), 128.

[28] M.T. Liu, W.T. Cheng, M.J. Li, H.N. Liu, D.M. Yang and S.Y. Lin, Arch. Dermatol. Res. 297 (2005), 231.

[29] J.M. Ouyang, L. Duan and B. Tieke, Langmuir 19 (2003), 8980.

[30] E.P. Paschalis, E. DiCarlo, F. Betts, P. Sherman, R. Mendelsohn and A.L. Boskey, Calif. Tissue Int. 59 (1996), 480.

[31] C.H. Petter, N. Heigl, M. Rainer, R. Bakry, J. Pallua, G.K. Bonn and C.W. Huck, Currt. Medl. Chem. 16 (2009), 318.

[32] S.J. Prestrelski, N. Tedeschi, T. Arakawa and J.F. Carpenter, Biophys. J. 65 (1993), 661.

[33] C. Rey, B. Collins, T. Goehl, I.R. Dickson and M.J. Glimcher, Calif. Tissue Int. 45 (1989), 157.

[34] C. Rey, V. Renugopalakrishnan, M. Shimizu, B. Collins and M.J. Glimcher, Calif. Tissue Int. 49 (1991), 259.

[35] P. Richette, T. Bardin and M. Doherty, Rheumatology 48 (2009), 711.

[36] A.K. Rosenthal, Curr. Opin. Rheumatol. 19 (2007), 158.

[37] A.B. Sønju Clasen and I.E. Ruyter, Adv. Dent. Res. 11 (1997), 523.

[38] H. Susi and D.M. Byler, Biochem. Biophys. Res. Commun. 115 (1983), 391.

[39] P. Taddei, E. Modena, A. Tinti, F. Siboni, C. Prati and M.G. Gandolfi, J. Mol. Struct. 993 (2011), 367.

[40] V. Untereiner, O. Piot, M.D. Diebold, O. Bouché, E. Scaglia and M. Manfait, Anal. Bioanal. Chem. 393 (2009), 1619.

[41] D.L. Wetzel and S.M. LeVine, Science 285 (1999), 1224.

[42] J. Xie, C. Riley, M. Kumar and K. Chittur, Biomaterials 23 (2002), 3609. 


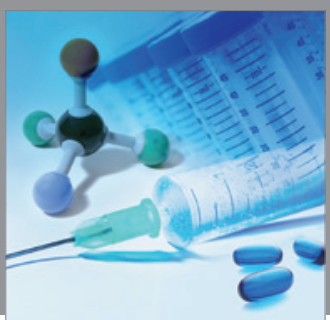

International Journal of

Medicinal Chemistry

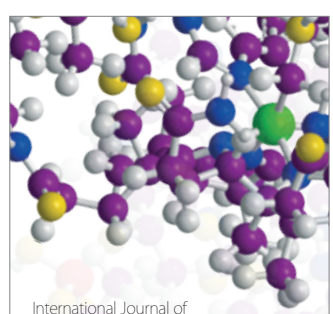

Carbohydrate Chemistry

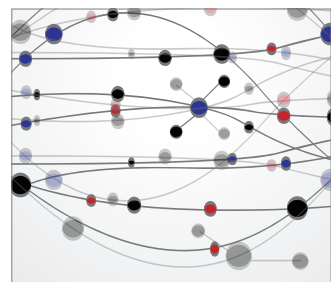

The Scientific World Journal
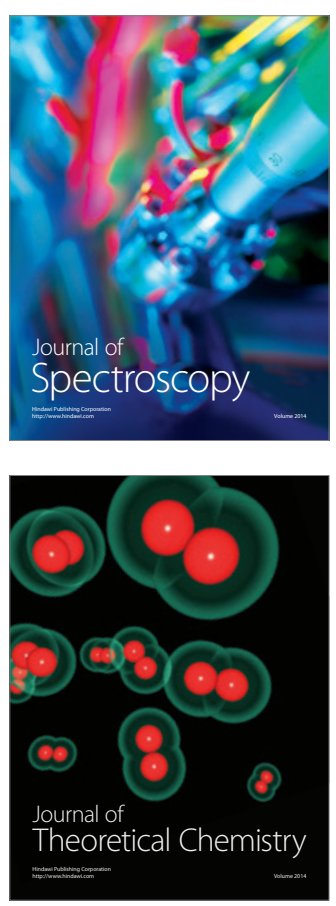
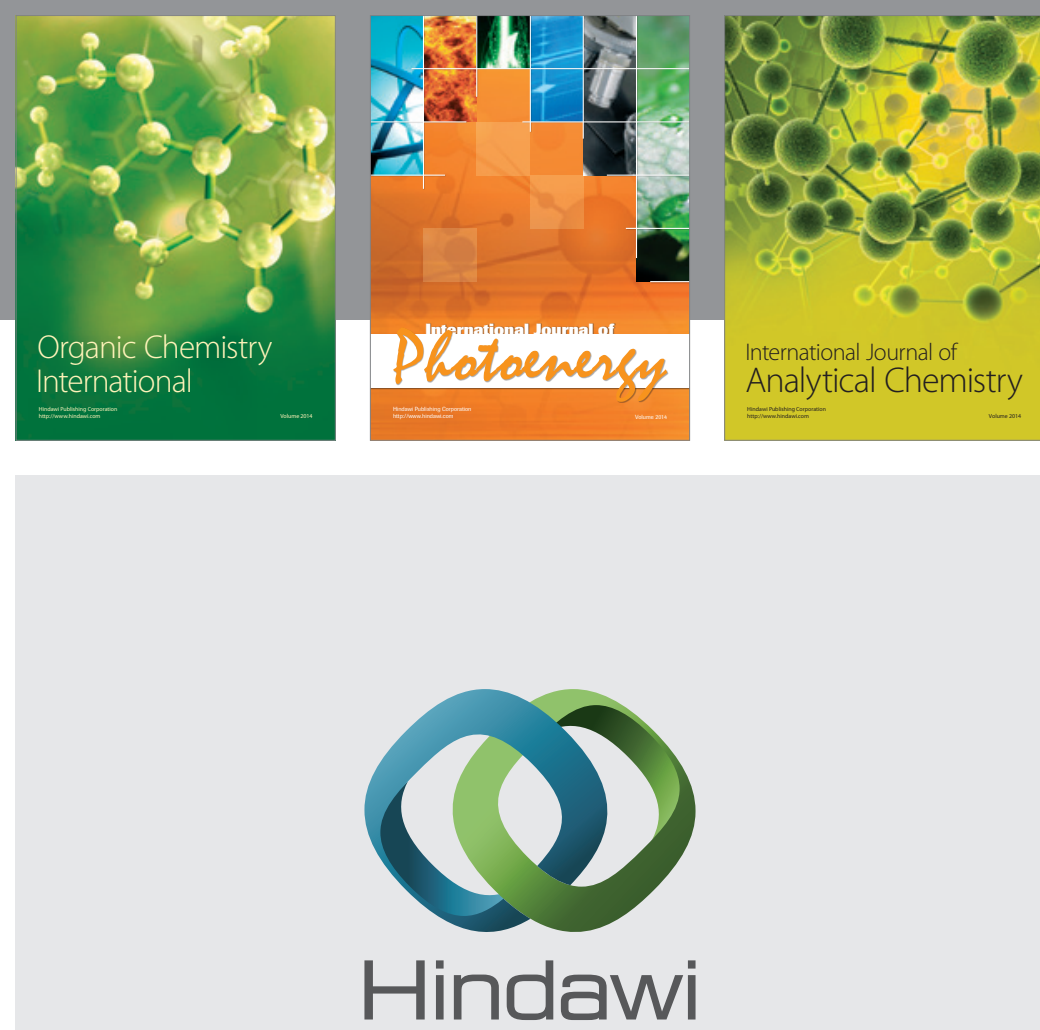

Submit your manuscripts at

http://www.hindawi.com
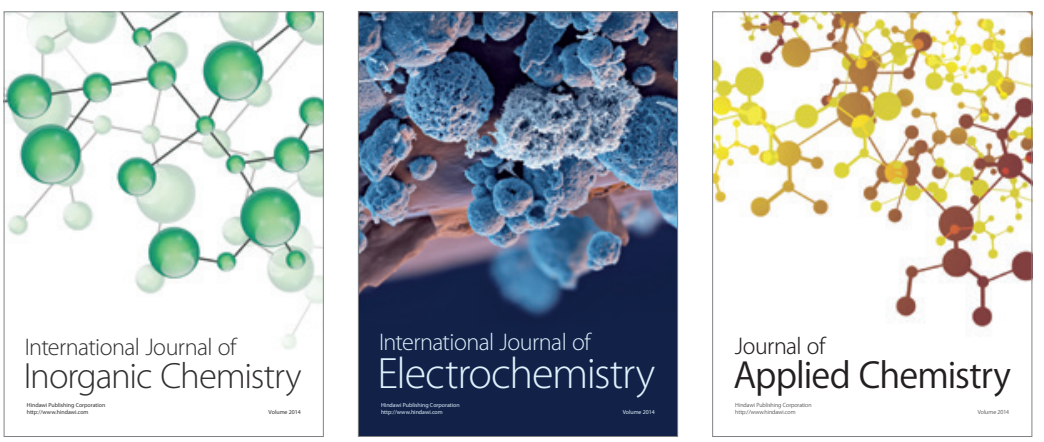

Journal of

Applied Chemistry
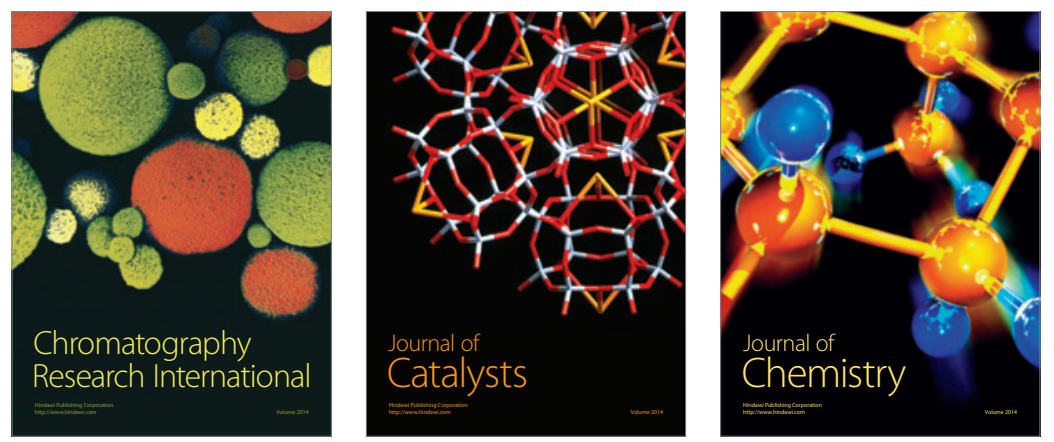
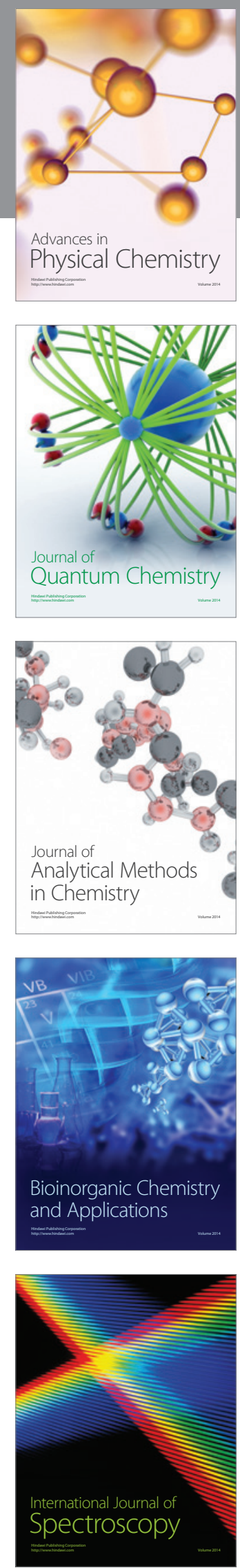